\title{
PENGARUH PERUBAHAN LOGO (REBRANDING) TERHADAP CITRA PERUSAHAAN PADA PT BANK BRI TBK
}

\author{
Nuzul Inas Nabila ${ }^{1)}$
}

1) dosen universitas pamulang, email : nuzulinasnabilaa@gmail.com

\section{ARTICLES}

ABSTRACT

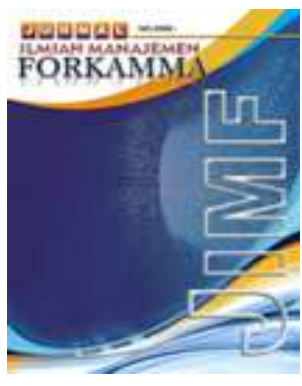

\section{JURNAL ILMIAH MANAJEMEN FORKAMMA}

Vol.2, No.1, November 2018 Halaman : $117-126$

(c) LPPM \& FORKAMMA

Prodi Magister Manajemen UNVERSITAS PAMULANG

ISSN (online) : 2599-171X ISSN (print) : :2598-9545

\section{Keyword :}

Perubahaan Logo, Citra Perusahaan

JEL. classification :

C31, E50

\section{Contact Author :}

\section{PRODI \\ MAGISTER MANAJEMEN \& FORKAMMA UNPAM \\ JL.Surya Kencana No.1 Pamulang \\ Tangerang Selatan - Banten \\ Telp. (021) 7412566, Fax (021) 7412491 Email : \\ jurnalforkamma.unpam@gmail.com}

Penelitian ini bertujuan untuk mengetahui pengaruh perubahan logo (rebranding) terhadap citra perusahaan yang dilakukan oleh PT Bank BRI Tbk. Hipotesis dalam penelitian ini adalah Perubahan logo PT Bank BRI Tbk berpengaruh terhadap citra perusahaan. Data diperoleh dari penyebaran kuesioner dengan metode non probability sampling dengan teknik purposive sampling. Sampel yang diambil 100 responden nasabah Bank BRI. Alat analisis yang digunakan yaitu regresi sederhana. Hasil analisis data diperoleh pengaruh perubahan logo terhadap citra merek sebesar $r^{2}=0,342$. Hal ini berarti sumbangan variabel $\mathrm{x}$ (perubahan logo) berperan dalam mempengaruhi setiap penambahan variabel y (citra perusahaan) sebesar $34,2 \%$. Hal ini menunjukkan bahwa perubahan logo PT Bank Rakyat Indonesia (BRI) memberi pengaruh $34,2 \%$ terhadap citra perusahaan. Pengujian Hipotesis menunjukan bahwa thitung lebih besar dari ttabel yaitu 7,136>1.984 artinya perubahan logo (rebranding) berpengaruh secara signifikan terhadap citra perusahaan pada PT Bank Rakyat Indonesia (BRI) Tbk.

This study aims to determine the effect of logo changes (rebranding) on corporate image conducted by PT Bank BRI Tbk.. Hypothesis in this study is the change of logo of PT Bank $B R I$ Tbk affect the image of the company. Data were obtained from questionnaires distribution with non probability sampling method with purposive sampling technique. Samples taken 100 customer respondents Bank BRI. The analysis tool used is simple regression. The result of data analysis obtained the effect of logo change on brand image of $r^{2}=0,342$. This means the contribution of variable $x$ (logo change) plays a role in influencing each addition of variable y (corporate image) of $34.2 \%$. This shows that the change of logo of PT Bank Rakyat Indonesia (BRI) gives $34,2 \%$ influence to company image. Hypothesis Testing showed that thitung bigger than ttable that is 7,136> 1,984 mean change of logo (rebranding) have an effect on significantly to company image at PT Bank Rakyat Indonesia (BRI) Tbk. 


\section{A. Pendahuluan}

Persaingan yang semakin ketat baik antar perusahaan domestik maupun dengan perusahaan asing serta adanya perkembangan teknologi dan informasi yang semakin canggih seperti sekarang ini, menjanjikan suatu peluang dan tantangan bisnis baru bagi perusahaan yang beroperasi di Indonesia, keadaan tersebut memunculkan inovasi dan perubahan-perubahan strategi dalam suatu perusahaan. Strategi persaingan perusahaan agar tetap eksis dan berkembang yaitu dengan merubah identitas perusahaan dengan cara mengganti logo.

Merek merupakan sebuah nama atau simbol (seperti logo, merek dagang, desain kemasan, dan sebagainya) yang dibuat untuk membedakan satu produk dengan produk lainnya (Surachman, 2008:14). Merek memegang peranan yang sangat penting, salah satunya sebagai pengenal dan tanda kepada konsumen atau pesaing lainnya dengan adanya merek dapat menjembatani harapan konsumen pada saat perusahaan menjanjikan sesuatu kepada konsumen. Sehingga dapat diketahui adanya ikatan emosional yang tercipta antara konsumen dengan perusahaan penghasil produk atau jasa melalui merek.

Menurut Kotler (2002:460) salah satu elemen merek yang mampu memberikan kontribusi yang positif dalam penciptaan merek yang ideal yaitu logo dan simbol. Logo dan simbol merupakan seperangkat gambar atau huruf yang diciptakan untuk mengindikasikan keorisinilan, kepemilikan ataupun asosiasi. Walaupun kunci elemen dalam merek adalah nama merek, namun logo dan simbol juga merupakan suatu elemen yang diingat dalam ingatan seseorang. Sehingga, penciptaan logo dan simbol sangat penting agar dapat dikaitkan dengan suatu nama merek didalam ingatan pelanggan.

Logo menjadi sebuah pengakuan, kebanggan, inspirasi kepercayaan, kehormatan, kesuksesan, loyalitas dan keunggulan yang tersirat ke dalam suatu bentuk atau gambar. Logo juga merupakan bagian yang penting untuk menunjukkan keberadaan suatu pembeda produk dengan produk lainnya. Logo diyakini dapat memberikan efek pengakuan tertentu kepada setiap orang yang melihat atau memakai. Perusahaan banyak melakukan perubahan logo agar lebih menarik dengan Rebranding.

Lebih khusus lagi, rebranding dikategorikan ke dalam jenis yang berbeda berdasarkan nama, logo dan slogan perubahan. Mungkin ada lima jenis rebranding yaitu nama baru dan logo, nama baru, logo baru dan slogan, logo baru saja, dan hanya slogan baru (Stuart dan Muzellec, 2004). Rebranding sebagai sebuah perubahan merek, seringkali identik dengan perubahan logo ataupun lambang sebuah merek. Dengan kata lain, ketika melakukan rebranding maka yang berubah ialah nilai-nilai dalam merek itu sendiri.

Pada artikel yang sama dikemukakan beberapa alasan lain dilakukannya rebranding dalam sebuah perusahaan yaitu:

1. Identitas dari perusahaan tersebut tidak dapat mewakili pelayanan dari perusahaan tersebut.

2. Perusahaan tersebut sudah memiliki reputasi yang buruk di mata masyarakat.

3. Perusahaan tersebut ingin memberikan sesuatu yang baru, berupa pembenahan dalam perusahaan (Mazwahid, 2012)

Rebranding memakan waktu yang lama karena harus mempertimbangkan beberapa faktor, diantaranya faktor internal dan eksternal. Faktor internal misalnya, perusahaan harus mempertimbangkan secara matang apakah perubahan ini membawa pengaruh 
yang besar bagi karyawannya dalam menjalankan tugasnya, karena karyawan harus memperkenalkan kembali logo baru tersebut ke masyarakat. Faktor eksternal ialah masyarakat dan stakeholder.

Identitas (termasuk logo) merupakan salah satu faktor penting yang mempengaruhi keberhasilan pembentukan citra merek. Hal ini disebabkan karena seperti halnya dalam kehidupan orang-perorangan, identitas perusahaan membentuk kesan pertama (Sutojo, 2004:18). Citra merupakan seperangkat keyakinan, ide, dan kesan yang dimiliki oleh seseorang terhadap suatu merek. Kotler mengatakan bahwa sikap dan tindakan konsumen terhadap suatu merek sangat ditentukan oleh citra merek tersebut (Simamora, 2006:23).

Perusahaan memerlukan identitas yang dapat membedakannya dengan perusahaan lain untuk membentuk citra merek perusahaan tersebut. Identitas perusahaan mewakili karakter perusahaan yang dapat menciptakan citra di benak masyarakat yang melihatnya. Identitas perusahaan itu sendiri adalah semua perwakilan atau perwujudan media visual dan fisik yang menampilkan suatu jati diri organisasi, sehingga dapat membedakan organisasi tersebut dengan organisasi lainnya (Bagus, 2011). Salah satu perusahaan yang pernah melakukan perubahan logo antara lain Bank BRI (Bank Rakyat Indonesia).

Persaingan bisnis sektor perbankan yang semakin ketat, menuntut pihak perusahaan untuk memikirkan kembali misi dan strategi bisnis yang baik, maka tidak menutup kemungkinan perusahaan tersebut akan kalah dalam persaingan. Menghadapi persaingan tersebut, setiap perusahaan memiliki strategi tersendiri agar tetap eksis. Strategi manajemen perusahaan agar tetap eksis dan berkembang adalah dengan merubah identitas perusahaan dengan mengganti Logo. Perusahaan memerlukan umpan balik dari konsumen untuk melihat seberapa baik perubahan logo yang dilakukan, serta apa yang dipikirkan konsumen ketika mereka melihat logo tersebut. Salah satu perusahaan di Indonesia yang merubah logonya ialah Bank Rakyat Indonesia (BRI) Tbk, dengan merubah logo dari bentuk, jenis, huruf, warna, dan slogan/tagline.

\section{B. Perumusan Masalah}

Berdasarkan latar belakang masalah di atas maka masalah yang akan dibahas dan dicari jawabannya dalampenelitian ini adalah :

1. Apakah Perubahan Logo (Rebranding) berpengaruh terhadap citra perusahaan pada PT. Bank Rakyat Indonesia (BRI) Tbk ?

\section{Tujuan Penelitian}

Berdasarkan rumusan masalah diatas, adapun tujuan penelitian ini untuk mengetahui pengaruh perubahan logo (rebranding) terhadap citra perusahaan yang dilakukan oleh PT. Bank Rakyat Indonesia (BRI) Tbk.

\section{Landasan Teori}

Istilah rebranding digunakan untuk menjelaskan tiga peristiwa penting, yaitu perubahan nama, perubahan merek secara estetika (warna, logo), ataupun reposisioning merek (Muzellec dan Lambkin, 2006).

Muzellec dan Lambkin (2006) mendefinisikan rebranding sebagai "the practice of building a new a name representative of a differentiated position in the mind frame of stakeholders and a distinctive identity from competitor." Berdasarkan definisi tersebut 
dapat dinyatakan bahwa rebranding merupakan upaya yang dilakukan oleh perusahaan dalam rangka mengubah citra perusahaan melalui perubahan nama yang lebih representatif serta membedakannya dari pesaing. Secara spesifik, perubahan merek (rebranding) dikelompokkan berdasarkan tiga tipe yang berbeda, yaitu perubahan nama, logo dan perubahan slogan. Namun perubahan merek (rebranding) juga dapat dikelompokkan menjadi lima jenis yaitu nama baru dan logo, nama baru, logo dan slogan baru, logo baru dan hanya slogan saja yang baru (Stuart dan Muzellec, 2004).

Logo memiliki peran utama sebagai identitas visual perusahaan yang dapat menciptakan emosi positif, menyampaikan makna ataupun meningkatkan pengakuan terhadap perusahaan dan merek (Van Der Lans et al, 2009). Sebagai elemen merek, logo dapat didefinisikan sebagai representasi grafis atau gambar yang memicu asosiasi memori dari target merek (Walsh, Winterick, Mittal, 2010).

Kohli et al (2002) dalam Alshebil (2007) memberikan beberapa pedoman ketika logo berubah, maka perubahan harus dibuat dalam (1) konten, apabila disebabkan oleh pergeseran dalam strategi merek, atau (2) gaya, ketika dirasakan adanya kebutuhan untuk update. Penelitian yang dilakukan oleh Walsh, Winterich dan Mittal (2010) tentang perubahan logo menunjukkan bahwa semakin banyak perubahan yang dilakukan perusahaan terhadap logo akan membuat konsumen yang berkomitmen yang tinggi terhadap perusahaan memiliki sikap yang negatif terhadap merek, sedangkan konsumen dengan komitmen yang lemah bereaksi positif terhadap perubahan tersebut.

Sejumlah penelitian yang dilakukan oleh Pimentel dan Heckler (2000) dalam Alshebil (2007) mempelajari persepsi konsumen terhadap perubahan logo. Melalui sejumlah penelitian, mereka menemukan bahwa konsumen lebih menyukai logo awal (logo yang tidak berubah), namun konsumen masih mentolerir perubahan kecil terhadap logo.

Menurut Kotler (2005:629) citra atau image adalah seperangkat keyakinan, ide dan kesan yang dimiliki oleh seseorang terhadap suatu objek. Image juga didefinisikan sebagai penglihatan secara keseluruhan atau sebuah objek dan serangkaian gambaran mental dan perasaan yang ditimbulkan. Citra yang dibentuk harus jelas dan memiliki keunggulan bila dibandingkan dengan pesaingnya. Saat perbedaan dan keunggulan merek dihadapkan dengan merek lain, muncullah posisi merek. Pada hakikatnya sama dengan proses persepsi, karena citra terbentuk dari persepsi yang telah terbentuk lama. Setelah melalui tahap yang terjadi dalam proses persepsi, kemudian dilanjutkan pada tahap keterlibatan konsumen.

"Citra perusahaan adalah citra dari suatu organisasi secara keseluruhan, jadi bukan hanya citra atas produk dan pelayannya."(Jefkins, 1994:19) dalam Kartika (2010:24). "Citra perusahaan merupakan sekumpulan kepercayaan dan perasaan tentang organisasi" (Dowling, 2001) dalam Kartika (2010:24). Pentingnya citra perusahaan dikemukakan oleh Gronroos (Kartika, 2010:25), sebagai berikut:

1. Menceritakan harapan bersama kampanye pemasaran eksternal. Citra positif memberikan kemudahan perusahaan untuk berkomunikasi dan mencapai tujuan secara efektif sedangkan citra negatif sebaliknya.

2. Sebagai penyaring yang mempengaruhi persepsi pada kegiatan perusahaan. Citra positif menjadi pelindung terhadap kesalahan kecil, kualitas teknis atau fungsional sedangkan citra negatif dapat memperbesar kesalahan tersebut.

3. Sebagai fungsi dari pengalaman dan harapan konsumen atas kualitas pelayanan perusahaan. 
4. Mempunyai pengaruh penting terhadap manajemen atau dampak internal. Citra perusahaan yang kurang jelas dan nyata mempengaruhi sikap karyawan terhadap perusahaan.

\section{E. Metodologi}

\section{Penentuan Populasi dan Sampel}

Penelitian ini menggunakan metode kuantitatif. Jenis penelitian yang digunakan adalah jenis penelitian eksplanatori (explanatory research). Penelitian eksplanatori adalah penelitian yang digunakan untuk menguji hipotesis tentang adanya hubungan variabelvariabel (sebab akibat).

Dari definisi tersebut, alasan pemilihan model ini dimaksudkan untuk membuat penjelasan mengenai hubungan sebab akibat yang diperoleh antar variabel yang diperoleh dengan fakta-fakta, sifat-sifat serta mengetahui seberapa besar kontribusi variabel-variabel bebas terhadap variabel terikatnya serta besar arah hubungan itu terjadi. Jadi penelitian yang dilakukan disini adalah penelitian penjelasan untuk menguji pengaruh perubahan logo terhadap citra perusahaan pada PT. Bank BRI (Tbk) di Indonesia.

Populasi menurut Suharsimi Arikunto (2002:108) merupakan keseluruhan subjek penelitian. Dalam penelitian kuantitatif, masalah yang sering dihadapi peneliti umumnya berkaitan dengan populasi yang diteliti. Populasi dalam penelitian ini adalah nasabah BRI (Bank Rakyat Indonesia) Tbk cabang Ciseeng Bogor

Sampel adalah sebagian individu dari populasi yang diteliti, yang dipandang dapat menggambarkan secara representative mengenai keadaan populasi (Arikunto, 2002:109). Pengambilan sampel dilakukan dengan menggunakan Non probability sampling yakni setiap responden memiliki kriteria populasi tidak memiliki kesempatan yang sama untuk menjadi sampel. Lebih tepatnya lagi metode pengambilan sampel ini bersifat convenience sampling, yaitu anggota populasi yang dipilih berdasarkan judgement peneliti. Peneliti memilih responden berdasarkan pengetahuan dan pandangan peneliti yang menilai bahwa seorang yang menjadi anggota populasi tersebut layak untuk menjadi sampel dalam penelitian ini. Sehingga, besarnya sampel dalam penelitian ini adalah 100 sampel perespon dari nasabah BRI (Bank Rakyat Indonesia) Tbk cabang Ciseeng, Bogor.

\section{Analisis Data}

Analisis ini digunakan untuk mengetahui bagaimana penilaian konsumen tentang Pengaruh perubahan logo terhadap citra perusahaan pada PT Bank BRI tbk. Model analisis yang digunakan adalah Analisis Regresi Sederhana. Model Regresi digunakan untuk mengansumsikan bahwa terdapat hubungan linear antara variabel perubahan logo dan citra perusahaan.

Adapun bentuk umum persamaan analisis regresi sederhana yang digunakan dalam penelitian ini adalah sebagai berikut:

$Y=a+b X+e$

Keterangan

$$
\begin{aligned}
& Y=\text { Citra Perusahaan } \\
& \mathrm{a}=\text { Nilai konstanta } \\
& \mathrm{X}=\text { Perubahan Logo } \\
& \mathrm{e}=\text { error }
\end{aligned}
$$




\section{Definisi variabel Operasional}

Pada penelitian ini terdapat dua variabel yang diteliti, antara lain perubahan logo (rebranding) dan citra perusahaan dimana untuk menguji hipotesis penelitian ini, maka setiap variabel diukur dengan menggunakan instrument variabel tersebut.

\section{F. Hasil dan Pembahasan}

Uji validitas mengacu pada sejauh mana perbedaan skor skala pengamatan yang mencerminkan perbedaan sebenarnya antara objek berdasarkan karakteristik yang sedang diukur, dibandingkan dengan kesalahan sistematik dan kesalahan acak. Uji reliabilitas mengacu pada sejauh mana alat ukur mampu memberikan hasil yang konsisten jika dilakukan pengukuran berulang kali dan uji validitas.

Tabel 1 Uji Validitas

\begin{tabular}{|c|c|c|c|c|c|c|}
\hline \multicolumn{2}{|l|}{ Variabel } & \multirow[t]{2}{*}{$\mathrm{KMO}$} & \multirow[t]{2}{*}{ MSA } & \multirow[t]{2}{*}{ Communalities } & \multirow{2}{*}{$\begin{array}{c}\text { Component } \\
\text { Matrix }\end{array}$} & \multirow{2}{*}{$\begin{array}{c}\text { Kriteria } \\
\text { Validitas }\end{array}$} \\
\hline$x$ & Indikator & & & & & \\
\hline \multirow{8}{*}{$\begin{array}{l}\text { Perubahan } \\
\text { Logo }\end{array}$} & $\begin{array}{l}\text { Bentuk logo } \\
\text { atau desain } \\
\text { logo lebih } \\
\text { menarik }\end{array}$ & \multirow{8}{*}{0,769} & 0,845 & 0,530 & 0,679 & Valid \\
\hline & $\begin{array}{l}\text { Bentuk logo } \\
\text { atau desain } \\
\text { logo mudah } \\
\text { diingat }\end{array}$ & & 0,796 & 0,562 & 0,732 & Valid \\
\hline & $\begin{array}{l}\text { Huruf logo jelas } \\
\text { untuk dibaca }\end{array}$ & & 0,746 & 0,756 & 0,646 & Valid \\
\hline & $\begin{array}{l}\text { Huruf mudah } \\
\text { dipahami }\end{array}$ & & 0,789 & 0,472 & 0,664 & Valid \\
\hline & $\begin{array}{l}\text { Warna eye } \\
\text { catching lebih } \\
\text { terang dan } \\
\text { menonjolkan } \\
\text { image }\end{array}$ & & 0,738 & 0,508 & 0,657 & Valid \\
\hline & $\begin{array}{l}\text { Mempunyai } \\
\text { makna berbeda } \\
\text { dari setiap } \\
\text { warna yang } \\
\text { ada }\end{array}$ & & 0,859 & 0,552 & 0,658 & Valid \\
\hline & $\begin{array}{l}\text { Mudah } \\
\text { diucapkan } \\
\text { slogan atau } \\
\text { logo }\end{array}$ & & 0,671 & 0,824 & 0,679 & Valid \\
\hline & $\begin{array}{l}\text { Mudah } \\
\text { dimengerti } \\
\text { slogan dan arti } \\
\text { slogan }\end{array}$ & & 0,760 & 0,727 & 0,712 & Valid \\
\hline
\end{tabular}




\begin{tabular}{|c|c|c|c|c|c|c|}
\hline \multicolumn{2}{|l|}{ Variabel } & \multirow[t]{2}{*}{$\mathrm{KMO}$} & \multirow[t]{2}{*}{ MSA } & \multirow[t]{2}{*}{ Communalities } & \multirow{2}{*}{$\begin{array}{l}\text { Component } \\
\text { Matrix }\end{array}$} & \multirow{2}{*}{$\begin{array}{c}\text { Kriteria } \\
\text { Validitas }\end{array}$} \\
\hline$Y$ & Indikator & & & & & \\
\hline \multirow{3}{*}{$\begin{array}{l}\text { Citra } \\
\text { Perusahaan } \\
\text { (Y) }\end{array}$} & $\begin{array}{l}\text { Perubahan } \\
\text { logo } \\
\text { menambah } \\
\text { kepercayaan } \\
\text { terhadap Bank } \\
\text { BRI }\end{array}$ & \multirow{3}{*}{0,715} & 0,720 & 0,765 & 0,875 & Valid \\
\hline & $\begin{array}{l}\text { Logo baru } \\
\text { memberi } \\
\text { kesan yang } \\
\text { lebih menarik }\end{array}$ & & 0,671 & 0,819 & 0,905 & Valid \\
\hline & $\begin{array}{l}\text { Logo baru } \\
\text { menambah } \\
\text { gagasan } \\
\text { perubahan } \\
\text { terhadap Bank } \\
\text { BRI }\end{array}$ & & 0,771 & 0,725 & 0,851 & Valid \\
\hline
\end{tabular}

Sumber: output SPPS 18

Berdasarkan Tabel 4.1 uji validitas diatas, dapat diketahui bahwa semua indikator penelitian (11 indikator) memenuhi kriteria uji validitas sehingga dapat dianalisis lebih lanjut. Setelah dilakukan uji validitas, selanjutnya dilakukan pengujian reliabilitas konstruk yang akan digunakan dalam penelitian. Pengujian reliabilitas menggunakan cronbach's coefficient alpha dengan bantuan software SPSS. Koefisien alpha cronbach bernilai antara 0 sampai dengan 1 dan batasan nilai alpha cronbach yang umum digunakan adalah lebih besar sama dengan $0,7(\geq 0,7)$. Nilai alpha cronbach kurang dari $0,6(<0,6)$ menindikasikan bahwa realibilitas dari instrumen yang digunakan kurang memenuhi (Hair et al, 2006).

Tabel 3 Uji Reliabilitas

\begin{tabular}{|c|c|c|}
\hline Variabel Latent & $\begin{array}{l}\text { Koefisien reliabilitas } \\
\text { Cronbach's Alpha }\end{array}$ & Kriteria Uji \\
\hline $\mathrm{X}$ & 0,830 & Reliabel \\
\hline (Perubahan Logo) & 0,849 & Reliabel \\
\hline $\mathrm{Y}($ Citra Perusahaan) & & \\
\hline
\end{tabular}


Sumber: Output SPSS 18

\section{Hasil Analisis Data}

Pada penelitian ini untuk mengetahui pengaruh perubahan logo (rebranding) terhadap citra perusahaan pada PT Bank BRI TBk digunakan analisis regresi sederhana yang perhitungannya dilakukan dengan program SPSS versi 18.0. Hasil perhitungan tersebut dapat dilihat pada tabel

Tabel 4 Hasil Perhitungan Regresi Linier Sederhana Pengaruh Perubahan Logo (rebranding) terhadap Citra Perusahaan

Model Summary

\begin{tabular}{|c|c|c|c|c|}
\hline Model & $\mathrm{R}$ & $\mathrm{R}$ Square & Adjusted R Square & $\begin{array}{c}\text { Std. Error of the } \\
\text { Estimate }\end{array}$ \\
\hline \begin{tabular}{cc|c|c|c|} 
dimension \\
0
\end{tabular} & $.585^{\mathrm{a}}$ & .342 & .335 & 1.99738 \\
\hline
\end{tabular}

Predictors: (Constant), Perubahan logo

Sumber: Output SPSS 18

Berdasarkan tabel di atas maka diperoleh pengaruh perubahan logo terhadap citra perusahaan $\left(r^{2}\right)$ sebesar 0,342 hal ini berarti sumbangan variabel $x$ (perubahan logo) berperan dalam mempengaruhi setiap penambahan variabel y citra perusahaan $34,2 \%$ dan 65,8 \% sisanya dipengaruhi oleh faktor lain. Pengaruh perubahan logo dinilai memberikan kontribusi 34,2 \% terhadap citra perusahaan, karena logo yang baru belum dikenal oleh para konsumen.

Tabel 5 Persamaan Regresi Sederhana Pengaruh Perubahan Logo (rebranding) Terhadap Citra Perusahaan Coefficients $^{a}$

\begin{tabular}{|c|c|c|c|c|c|}
\hline \multirow[t]{2}{*}{ Model } & \multicolumn{2}{|c|}{$\begin{array}{l}\text { Unstandardized } \\
\text { Coefficients }\end{array}$} & \multirow{2}{*}{\begin{tabular}{|c|}
$\begin{array}{c}\text { Standardized } \\
\text { Coefficients }\end{array}$ \\
Beta \\
\end{tabular}} & \multirow[b]{2}{*}{$\mathrm{T}$} & \multirow[b]{2}{*}{ Sig. } \\
\hline & $B$ & Std. Error & & & \\
\hline $1 \quad$ (Constant) & -.224 & 1.701 & & -.132 & .895 \\
\hline $\begin{array}{c}\text { Perubahan } \\
\text { Logo }\end{array}$ & .358 & .050 & .585 & 7.136 & .000 \\
\hline
\end{tabular}

a. Dependent Variable: Citra Perusahaan

Sumber: Output SPSS 18 
Persaman Regresi Linier Sederhana yang diperoleh adalah:

\section{$Y=-2,24+0,585 x$}

Pengujian regresi di atas dilakukan pada taraf signifkan 95\% ( $\alpha=5 \%)$

Nilai $\beta$ persamaan regresi bernilai positif 0,585 . Hal ini membuktikan bahwa perubahan logo memberi pengaruh positif terhadap citra perusahaan. Selanjutnya dilakukan pengujian hipotesis untuk mengetahui signifikansi pengaruh perubahan logo terhadap citra merek dengan menggunakan uji $t$, yaitu membandingkan nilai $t_{\text {hitung }}$ dengan $t_{\text {tabel }}$ pada taraf signifikan $95 \%$ atau dengan a 0,05 serta menggunakan derajat kebebasan df (degree freedom).

$$
\mathrm{Df}=\mathrm{n}-\mathrm{k}-1=100-1-1=98
$$

Diperoleh nilai t Tabel $(0,05 ; 98)=1,984$ (lampiran)

Ketentuannya adalah jika $t_{\text {hitung }}>t_{\text {tabel }}$ maka ada signifikansi, sebaliknya jika $t_{\text {hitung }}<t_{\text {tabel }}$ maka tidak ada signifikansi.

Hasil pengujian hipotesis pengaruh perubahan logo terhadap citra merek dengan uji $\mathrm{t}$ dapat dilihat pada hasil uji t di bawah ini :

Tabel 5 Hasil Uji t

\begin{tabular}{|c|c|c|c|}
\hline Variabel & $t_{\text {hitung }}$ & $\begin{array}{c}t_{\text {tabel }} \text { pada tingkat } \\
\text { kepercayaan } 95 \%\end{array}$ & Kesimpulan \\
\hline $\begin{array}{c}\text { terhadap } \\
\text { Y }\end{array}$ & 7,136 & 1.984 & Ada pengaruh signifikan \\
\hline
\end{tabular}

Sumber: Output SPSS 18

Berdasarkan tabel di atas, maka besarnya nilai $t_{\text {hitung }}$ adalah 7,136 dan $t_{\text {tabel }}$ pada tingkat signifikan 95\% adalah 1.984 yang artinya perbandingan $t_{\text {hitung }}$ dengan $t_{\text {tabel }}$ adalah 7,136 > 1.984 atau $t_{\text {hitung }}$ lebih besar dari $t_{\text {tabel }}$ pada taraf signifikan 95\%, dengan demikian maka hipotesis penelitian diterima, artinya perubahan logo (rebranding) berpengaruh secara signifikan terhadap citra perusahaan pada PT Bank Rakyat Indonesia (BRI) Tbk

\section{G. Kesimpulan dan Saran}

\section{Kesimpulan}

Berdasarkan hasil analisis dan pembahasan tentang pengaruh perubahan logo (rebranding) terhadap citra perusahaan pada PT Bank Rakyat Indonesia (BRI) Tbk, maka dapat disimpulkan sebagai berikut

1.Pengaruh perubahan logo terhadap citra merek sebesar $r^{2}=0,342$. Hal ini berarti sumbangan variabel $x$ (perubahan logo) berperan dalam mempengaruhi setiap penambahan variabel y (citra perusahaan) sebesar $34,2 \%$. Hal ini menunjukkan bahwa perubahan logo PT Bank Rakyat Indonesia (BRI) memberi pengaruh 34,2\% terhadap citra perusahaan.

2.Pengujian Hipotesis menunjukan bahwa thitung lebih besar dari ttabel yaitu $7,136>1.984$ artinya perubahan logo (rebranding) berpengaruh secara signifikan terhadap citra perusahaan pada PT Bank Rakyat Indonesia (BRI) Tbk semakin melekat logo di benak konsumen dengan desain, warna, huruf dan slogan maka citra perusahaan akan berpengaruh positif di benak konsumen. 


\section{Saran}

Berdasarkan pembahasan dan kesimpulan dari hasil penelitian, mengenai pengaruh perubahan logo (rebranding) terhadap citra perusahaan pada PT Bank Rakyat Indonesia (BRI) Tbk maka saran yang dapat diberikan oleh peneliti antara lain

1. Sebaiknya kedepannya penelitian selanjutnya menggunakan faktor-faktor yang lain bukan hanya rebranding untuk citra perusahaan, dan juga sebaiknya penelitian selanjutnya meneliti kearah barang atau goods karena penelitian ini kearah jasa yaitu Bank BRI

2. Sebaiknya perusahaan memberikan promosi secara aktif melalui iklan, media cetak, baliho maupun reklame agar konsumen mengetahui Bank BRI melakukan rebranding, dengan cara mengingatkan pelanggan melalui promosi yang efektif maka Bank BRI akan lebih dikenal oleh konsumen dengan logo dan slogan yang baru dan menjadi sebuah gagasan atau ide yang membuat citra perusahaan BRI semakin membaik, dan pelanggan tidak memilih layanan ke produk lainnya.

\section{H. Daftar Pustaka}

Alshebil, Saleh Abdul Aziz. ( 2007). Consumer Perception of Rebranding: The Case of Logo Changes. Arlington: The Universityof Texas.

Arikunto, Suharsimi.(2002). Prosedur Penelitian Suatu Pendekatan Praktek.Jakarta Penerbit Rineka Cipta

Dowling, Grahame. 2001. Creating Corporate Reputation, Identify, Image, and Performance, New York:Oxford University Press

Groonroos, C. (2001).Service Management and Marketing , 2nd edition

Hadi ,Sulistio Bagus. (2011). Analisis Pengaruh Logo PT Telkom Indonesia Tbk

Hair J.F (2006). Multivariate Data Analysis. Edisi 5. Jakarta: Gramedia Pustaka. Utama.

Jefkins, Frank,..(1994), Public Relations Untuk Bisnis. Penerjemah : Frans Kowa, Pustaka Binaman Pressindo: Jakarta

Kartika. (2010). Pengaruh Sikap Penerima Program Corporate Social

Responsibility (CSR) Terhadap Citra Perusahaan (Corporate Image). Universitas Lampung: Bandar Lampung.

Kotler, Philip.(2002). Manajemen Pemasaran. Jakarta. Edisi Milenium.Prenhalido.

Kohli, Chiranjeev, Rajneesh Suri, and Mrugank Thakor (2002), "Creating Effective

Logos: Insights from Theory and Practice," Business Horizons, 45 (3), 58-64.

Kotler, Philip.(2005). Dasar-dasar Pemasaran .Jilid 2, Jakarta.Indeks Media Gramedia.

Mazwahid.( 2012). Mengapa Harus Rebranding? http://kampus.marketing.co.id. Diakses tanggal 29 Oktober 2012. 
Muzellec, Laurent; Lambkin, Mary. (2006). Corporate Rebranding: Destroying, Transferring or Creating Brand Equity. European Journal of Marketing. Vol 40. No 7. Page 803-824.

Nazir,Mohammad.(2003). Metodologi Penelitian. Jakarta. Ghalia Indonesia.

Pimentel, Ronald and Susan Heckler (2000), "Changes in Logo Designs: Chasing the Elusive Butterfly Curve," Working Paper, 1-24

S.A, Surachman, (2008). Dasar-Dasar Manajemen Merek. Malang : Bayu Media Publishing

Sekaran, U.(2006). Research Method For Business : Metodologi Penelitian Untuk Bisnis. Buku 2. Edisi 4. Jakarta: Salemba Empat

Simamora, Bilson.(2006). Panduan Riset Perilaku Konsumen. Jakarta PT Gramedia Pustaka utama.

Stuart, Helen; Muzellec, Laurent. (2004). Corporate Makeovers: Can a Hyena Rebrand? Journal of Brand Management. Vol 11. Vol 6. Page 472-483.

Sutojo, Siswanto. (2004). Membangun Citra Perusahaan. Jakarta: Damar Mulia Pustaka.

Walsh,M.F; Winterich, K.P.; Mittal, V.( 2010). Do Logo Redesigns Help or Hurt Your Brand? The Role of Brand Commitment. Journal of Product and Brand Management. Vol 19. No 2. Page 76-84.

Van der Lans, R. (2009). Cross National Logo Evaluation Analysis: An Individual sLevel Approaches. Marketing Science. Vol 28. No.5. Page 968-985. 